\title{
LA CASA DE ADOBE, UN REFERENTE CULTURAL DE LA IDENTIDAD COSTARRICENSE
}

\begin{abstract}
Resumen
El desconocimiento de los referentes culturales propicia la fijación de un estereotipo; por consiguiente, es importante adquirir herramientas para la comprensión cultural y la validación de los referentes. La casa de adobe, para los costarricenses, es un elemento constitutivo de la conciencia colectiva y parte de la identidad que evidencia su vitalidad cultural; pero requiere de teorías como: habitar, paisaje, inteligencias múltiples, reflexión, comprensión y creatividad; así se validarán las imágenes visibles y las no visibles, de tal forma que una casa de adobe se convierte en "terruño", en habitar, en existencia, en realidad, en síntesis, en una verdad en sí misma.
\end{abstract}

Palabras claves: cultura, identidad, casa de adobe.

\begin{abstract}
The lack of knowledge of cultural models propitiate fixation of a stereotype, therefore it is important to acquire tools for cultural understanding and validation of its referents. For Costa Ricans, the adobe house is a constitutive element of collective consciousness and also part of their identity, to make evident their cultural vitality it requires theories such as: inhabit, landscape, multiple intelligences, reflection, understanding and creativity; so the visible and non-visible images, so be validated to an adobe house becomes "native land", to dwell in existence in reality and, therefore, a truth in itself.
\end{abstract}

Keywords: culture, identity, adobe house.

Gabriela

Campos Murillo.

Académica de la UNA y la

UNED. Egresada de Maestría en Español como Segunda Lengua, UCR, Licenciada en Docencia, UNED, Bachiller en

Filología Española, UCR gabriela.cmurillo@gmail.
La enseñanza de la cultura propicia el acercamiento con el "otro", el extranjero que me descubre y desde donde me redescubro; por esto, los referentes culturales como la casa de adobe, la comida o las direcciones, entre otros, se vinculan con la verdad que yace en la memoria de un pueblo.

Aquella verdad es lo trascendental, toda imagen, visible o no, "...que se convierte en un mecanismo ideológico" (Gustafsson; 2004: p. 137) cuya función es reafirmar nuestra propia identidad. La casa de adobe es exactamente eso para el costarricense, una imagen de elementos visibles e invisibles.

Por lo tanto, para reconocerla como un referente de identidad es imprescindible desarrollar la comprensión cultural, así el docente cuyo rol será determinante requiere implementar estrategias didácticas que potencien el acercamiento con aquellos referentes donde se han depositado los recuerdos de las verdades renacidas como rasgos identitarios. Los referentes reflejan parte de la construcción del ser nacional y su identidad, así la casa de adobe es una imagen de lo tradicional, de su hogar, su terruño, ahí donde surge y yace lo trascendental. 
Por una parte, se muestra la fijación del estereotipo a través de lo que los pintores de la época consideraron importante de perpetuar en la memoria (e impresionismo de la nueva tendencia de los años treinta, representado por pintores como Fausto Pacheco, entre otros) como el paisaje local dominado po un elemento arquitectónico colonial: la casa de adobes; de ella captaron la luz paisaje constituido por la casa, el "palo(s)" y la montaña, al respecto Molina cita:

Lo característico de los pintores costarricenses de las primeras décadas del siglo $X X$ fue inspirarse en el universo rural $y$, en especial, en uno de sus compromisos esenciales: la casa de adobe. (Molina; 2008: p. 43)

Por ejemplo, el pintor, arquitecto e ingeniero Teodorico Quirós se refería a ella como bella y apacible imagen de nuestro paisaje criollo

Así, tanto la casa de adobe, la carreta y el traje típico, se ubican al lado de los simbolos nacionales que representan la originalidad costarricense, lo cual se asume como un hechoy, en general, no se cuestionan, ya que el Estado y su aparato escolar se encargan

Por su parte, Gloria Aponte en su artículo "Paisaje e identidad" Io define "como formador del caracter, alimento del espiritu y estimulo de la creatividad" (Aponte. 2003, p. 153) y explica como el ser humano es un ser desprevenido La observación se reliza para descubrir la identidad culturato ident

La ontidad-nexo, contorno, indistintamente de que estas sean ajenas a él, este proceso decc El paisaje.

El paisaje costarricense está habitado por los elementos "vivos e inertes, naturales y antrópicos, es más dinámico y a la vez más vulnerable que otros objetos de la identidad" (Op. cit., p. 155) Su vulnerabilidad propicia un negar de nuestra .

Muere el que no posee un espacio en la memoria de la comunidad y vive aquel que es recordado a través del tiempo y cuya imagen es fijada, reproducida y defendida por cada uno de sus miembros, pues el espacio es una "...extensión representativa de la nación -como sociedad." (Montero; 2014: p. 193)

En ese sentido la casa de adobe es concebida desde dos perspectivas; por una parte, la identidad corporativa: logística y conceptual, lo "inmaterial", es lo que le muestro al otro, mi verdad, mi identidad, mi esencia, mi ser.

Y por otra parte, la imad, mi identidad, mi esencia, mi ser. material, esto es el identificador visual, según lo amplía Murillo en su artículo iUuuuupeee! Llamando a la casa de adobe. Un paisaje siempre verde, soliculo y cuyas casas están pinta la casa de adobe Un colores puros, de esta forma se ".. sustenta imaginario nacional." (Murillo; 2000: p. 112).

He aquí las asociaciones más frecuentes, relacionadas con la "casa típica costarricense": adobes, tejas, paisaje rural, piso de tierra, cocina de leña, abuelita en cocina, café chorreado, aguadulce, tortillas, interior en penumbra, humildad, tranquilidad y, azul y blanco. Azul y blanco en las casas, en la bandera y en el entorno. Pues en la casa de adobe normalmente se observa "...un contexto dominado por los colores de la bandera nacional: el azul de la montaña lejana, del cielo, de una eventual acequia, del zócalo y, a veces, de los marcos de puertas y ventanas, el blanco de las paredes y de una que otra nube; y el techo rojo de las tejas... (Molina, 2008, pp.43-44)
La deconstrucción y el remodelaje semántico de la casa de adobe activa los esquemas de la memoria colectiva e inicia el proceso dialógico con ese otro (texto del espacio cultural) que reproducen las voces de la memoria las que habitan dentro de sí como la herencia cultural, la esencia; este proceso dialógico lo sintetiza Baitín en el concepto del cronotopo: ". temporales y espaciales asimiladas en la literatura..." (1989, p.237).

Por su parte, Chen expone sobre la función del cronotopo: "propiedad colectiva moldeada constantemente al punto de que pasa como una "representación fa-miliar": de ahí su permanencia y su alto e inestimable poder de convocatoria cultural" (2004, p.34), entonces el lugar de referencia es el cronotopo inalterable al que se le otorga un valor social sacralizado al convertir la casa de adobe en el terruño.

El terruño es el punto cuando el nativo ve y desea mostrarle al otro (al extranjero) la vivencia inscrita en una unidad espacial hecha metáfora, que se inserta en el tiempo comprimido en el arte:

Hecha de adobe, troncos y tejas, en el regazo de una colina, estaba la casa, cuya fachada daba al Poniente.

En los atardeceres de marzo, el sol veíase del tamaño de una rueda de carreta

audaces y cálidos, como los cuadros del pobre Gauguin. (Salazar, 1990, p. 35)

Tanto en la pintura como en la escritura la casa de adobe por sí misma habita un lugar sagrado, pues en ella la presencia humana no es requerida para "ser". Y es que si los humanos residimos en las "cosas", estas adquieren un nuevo significado: el del símbolo, la unión de lo que Heidegger en su texto Construir, habitar, pensar (1951) concibe como cuaternidad: la integración del cielo, la tierra, los divinos y los mortales.

Todo objeto ("cosa") une de alguna manera a la cuaternidad. La casa de adobe es para la cultura costarricense un simbolo expreso de aspectos identitarios que protege al imaginario que tras ella se remodela en la pintura. Así, se une el cielo y la tierra con lo divino que se refleja en el hogar como centro' y el hombre quien lo habita.

La otra relación se esclarece al considerar los espacios cotidianos con lugares representativos de su esencia, donde radica el para que fue construido. Así de la relación entre lugares y espacios, y, espacios y espacios surge un punto de convergencia donde se apoya la relación hombre y espacio, segun Heidegger. La casa de adobe y sus imágenes constituyen lugares que simbólicamente representan al ser costarricense, el otro puede desconocerlas; pero para nosotros es un lugar habitado con memorias de la abuela, la comida típica, el campesino y el labriego sencillo del Himno Nacional.

Ahora bien, esta casa, como imagen, es uno de los tantos símbolos patrios que, junto con el traje y la carreta, se reconocen sin cuestionamiento alguno como identificadores visuales del espacio habitado en la cotidianeidad costarricense, aunque la casa sea la máscara o la apariencia, según Jean Chavalier (1999, p. 259); pero que aparenta aquello no plasmado en la pintura o la escritura: imágenes de sencillez, humildad, trabajo, ausencia, soledad y patriotismo (por los colores sintonizando con la bandera).

Khalil Gibran se expresa al respecto de la siguiente manera: "vuestra casa es vuestro cuerpo más dilatado", el cuerpo entendido a su vez como el receptáculo del alma. La casa es el refugio ante la intemperie y las inclemencias; es el lugar 
sagrado, "...un símbolo femenino, con el sentido de refugio, madre, protec ción..." (Chavalier; 1999: p. 259).

La casa de adobe es, por consiguiente, un templo ubicado en el centro de mundo, un palacio por la vista que posee y una fortaleza donde hay refugio, según Chavalier, quien a su vez reafirma lo expuesto por Heidegger al simboliza la cuaternidad en esta: "La casa del rey es pues as" una imagen del cosmos humano y a la vez un reflejo del cielo sobre la tierra" (Idem), donde está implícito

Pero cómo se logra que un estudiante de Español como Segunda Lengua (EL2) o más especificamente de C2 (Cultura del pais a donde se viaja o se va a estudiar), comprenda que el referente de identidad como la casa de adobe es una imagen sacralizada que habita en la memoria de un pueblo. Será a traves de estrategias donde se potencien las inteligemo as de Gardnercomo her a traves de estra volverse en el espacio sagrado.

Howard Gardner investigó el tema de las inteligencias múltiples, en un prime ro mom

$Y$ en un segundo momento de estudio, publica su libro La inteligencia reformulada. Las inteligencias múltiples en el siglo XXI, en el cual la definen como: "... un potencial biopsicologico para procesar información que se puede activar en para una cultura." (Gardnor, 2001: p. 45) Además incrpora tres inten un valor pararalista, existencial y espiritual, estas se suman a las ya expuestas: lógicomatemática, lingǘstica, lingǘstica, musical, sumacial, lar ya expustas. Iogicovez son agrupadas en tres grandes bl La inteligencianales.

Le refiere a lo corporal, lo cinestesico y lo espacial; la inteligencia interpersonal es la capacidad de entende deseos, miedos y capacidades del otro; y la intrapersonal es la comprensión de los factores afectivos.

Es mediante estos tres parámetros que el aprendiz podrá acercarse a la $C 2$ en estudio, procesar la información brindada por la imagen y los hablantes nativos para poder generar espacios de comprensión que le evitarán problemas culturales (choque cultural). ¿Qué tipos de problemas? Pues todos aquellos propios de la incomprensión o el desconocimiento: irrespeto, aburrimiento, falta de aprecio, etc. Observar la casa de adobe mediante los tres parámetros citados por Gardne implica un ver desde afuera, desde dentro y desde el otro. Es un mirar comprensivo que cuida de mi autoregulación y, de los sentimientos del otro y de los míos. Por su parte la inteligencia espiritual se enfoca en el misterio de la propia existencia: de la vida y la muerte que trasciende de la rutina y transforma lo expiritual como estado del ser, y posee un efecto en los demás.

Los contenidos espirituales perseguidos por el "buscador espiritual" pueden llegar a ser su ámbito, su valor de verdad y sus limitaciones, así si la verdad tiene un valor ancestral y heredado, no representa un problema si se le aplica la mirada subjetiva de la inteligencia espiritual, a esto se refiere la Dra. Amoretti cuando increpa al estudio "del pasado de nuestras verdades y no la verdad de nuestro pasado"

Eso es la casa de adobe "el pasado de nuestra verdad", pues implica la existencia de un algo físico como el fogón (cocina), la comida de la abuela, el piso de tierra, etc. todas ellas imágenes de identidad sobre el ser costarricense y ante

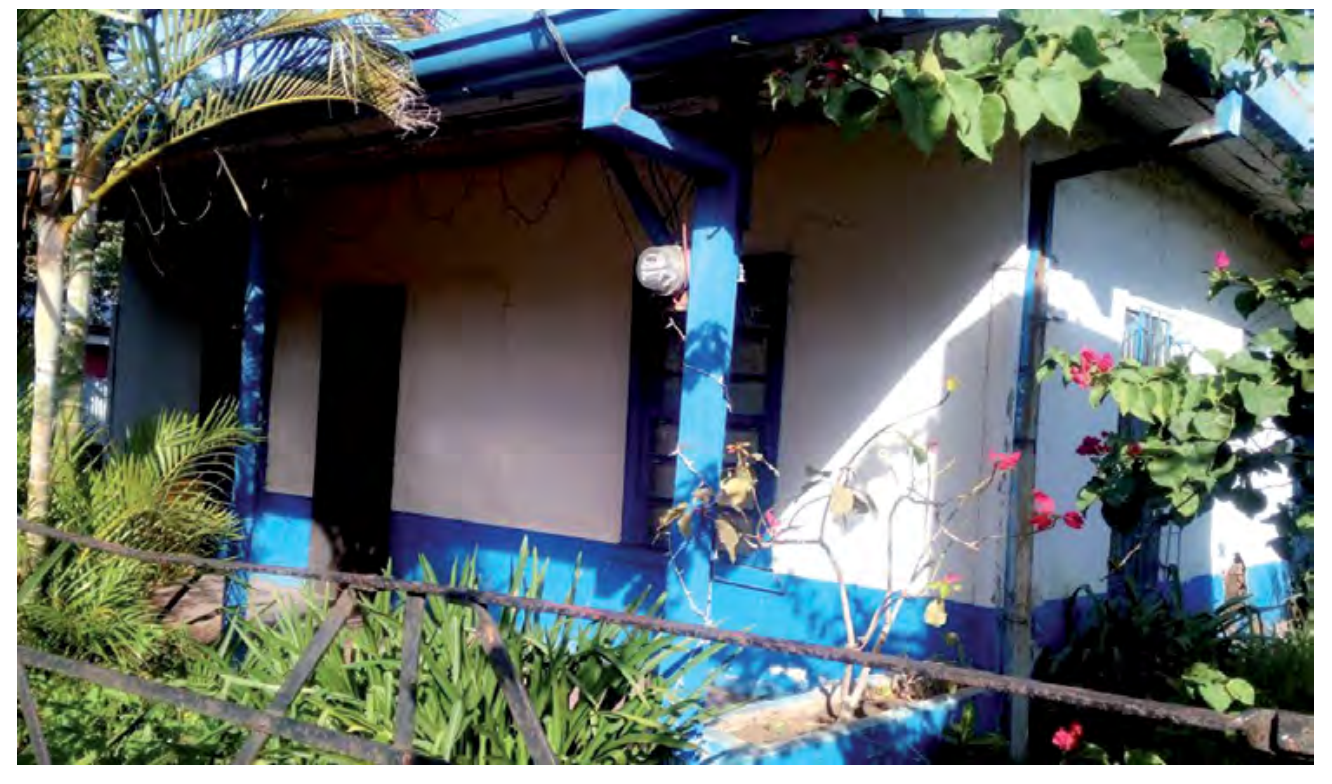

Foto 1. "Nuestra cas la casa de la tía Tere mamita Inés. Casa deder del año 1860 hoy desaparecida.

las cuales el extranjero puede sufrir crisis por la incomprensión al no poder "ver" aquello que solo yace en la memoria del pueblo.

Ahora bien, "la cultura y sus manifestaciones no tienen por qué sufrirse como si fueran una dictadura, si su vocación es la libertad" ${ }^{\prime \prime}$, por tal razón se requiere de la creación de espacios didácticos para propiciar sensibilidad y comprensión. Es así como el estudio de la cultura y sus referentes costarricenses logran que algunas personas se sientan más completas al entrar en contacto consigo mismas, mediante la relación cósmica reforzada por lo trascendental, es decir, la transmisión de lo culturalmente importante.

El efecto acumulativo de los procesos de comprensión cultural y la sensibilización, aunados al conocimiento concientizan al aprendiz de la C2 de que existe una verdad fuera de su propia verdad y lo conducen al cierre de los sufrimientos,

esto ocasiona la separación entre el "otro" y el "yo".
Y es que la comprensión se define como "...poder realizar una gama de actividades que requieren pensamiento en cuanto a un tema por ejemplo, explicarlo, explicarlo, encontrar evidencia y ejemplos, generalizarlo, aplicarlo, presentar analogias y por consiguiente, se sugiere a los..'(Perkins; 03 . p. 19 (tinas actividades cuya meta sea la comprensión y que propicie la evaluación continua y la retroalimentación Todo esto mediante retos progresivos y alcanzables, pues también se deben valorar las limitaciones del aprendiz, pues la intensión es que la C2 sea asequible. Sin ems tadio previo, la reflexión, la cual facilita el aumento de la creatividad, la flexibilidad y el uso de la información para poder exigirle al discente: "aplicar formas de dad y el uso de la información para poder exigirle al discente: "aplicar formas de perspectivas,o, remprometerse en plantear más opciones." (Ritchhart: 2000: pp. 27-28 [traducción persona])

Entonces, la creatividad amplía la comprensión y a su vez minimiza la fijación de las imágenes conductoras del estereotipo que margina y desacredita, el cual nace de los temores y los miedos por lo desconocido, lo diferente a su C1 (Cultura del hablante). Para evitar estos actos quien me visita ("el otro" de Bajtín) debe crear herramientas nuevas con información validada para comprender los aspectos identitarios circundantes a la casa de adobe y que reafirman el mandato "no 
matarás", lo cual implica: Respetarás la sacralidad de mis espacios, la existencia viva de lo que habita en mi memoria y no intentarás desacralizarlo, pues es $\mathrm{m}$ herencia, mi identidad, mis verdades.

Y para concluir, ¿cómo podría creerse que la pintura de una casa vieja, inexistente de forma tangible, es un espacio sagrado? Pues a partir de dos conceptos. El primero de ellos el cronotopo de Bajtín: "krono-topo", como una categoría cognoscitiva que valora y sacraliza los elementos percibidos por la mirada subjetiva del recuerdo, de acá que las relaciones tiempo y espacio estén siempr vigentes en los referentes culturales.

Y el segundo, la sacralización, propuesto por Villamán en la lectura "Acerca de las desacralizaciones del mundo moderno":

...en la cultura negra como en la indígena, nuestros muertos están vivos. Esta evidencia se internaliza de modo permanente en los procesos de socialización. Naturalmente están vivos de una manera diferente de la de nosotros "los vivos" y en un mundo diferente del nuestro. Hay pues una continuidad de la vida.

(1994, pp. 124-128)

Es así como esa casa de adobe que físicamente es cada vez más inexistente, no muere, pues se transforma para ser la "...percepción de la imagen como objeto visible y real..., según lo expone Montero $(2014, \mathrm{p} .193)$. Por tanto, es un elemen reflejo de mis rasgos identitarios y donde habita el pasado de mis verdades.

\section{Notas}

1. El Concepto de núcleo explicado por Chen (2004, p. 34)

2. Conceptos explicados por la Dra. María Amoretti Hurtado en sus clases de Cultura Maestría de Español como Segunda Lengua en la Universidad de Costa Rica.

3. Conceptos explicados por la Dra. María Amoretti Hurtado en sus clases de Cultura, Maestría de Español como Segunda Lengua en la Universidad de Costa Rica.

\section{Bibliografía}

Amoretti, M. (2009) La mirada antropológica del otro. Hacia una antropología de la liberación. Ponencia, II Congreso Internacional de Lingüística Aplicada. Universidad Nacional. Heredia, Costa Rica.

(2009) Material para los cursos de Claves Culturales I y II. (Antología: Tomo I: "Material 1: culturas de contexto alto y bajo", 73 - 75). Maestría de Español como Segunda Lengua, Universidad de Costa Rica, San José.

(2009) Material para los cursos de Claves Culturales I y II. (Antología: Tomo II: "Acerca de la desacralización del mundo moderno", 84 - 86.) Maestría de Español como Segunda Lengua, Universidad de Costa Rica, San José.
(1992) Diccionario de términos asociados en teoría literaria. Editorial de la Universidad de Costa Rica. San José, Costa Rica.

Aponte, G. (2003) "Paisaje e identidad cultural". Tabula Rasa. Revista de Humanidades. Universidad Colegio Mayo de Cundinamarca. Bogotá, Colombia. Páginas de la 153 a la 164. Recuperado el día 29 de junio de 2014, desde:
http://148.215.1.166:89/redalyc/pdf/396/39600107.pdf

Arroyo, C. (sf) Martin Heideer, Construir, habitar, pensar. Bauen, Wohnen, Denken. Cornell University para Promateriales. Recuperado el 3 de febrero de 2015, desde: $h t t p: / / w w w . p r o m a t e r i a l e s . c o m / p d f / p m 0511 . p d f$

Bajtín, M. (1989) "Las formas del tiempo y del cronotopo en la novela". Teoría y estética de la novela, pp. 239 - 409. Recuperado el 12 de setiembre de 2015, desde: http://132.248.101.21/filoblog/bubnova/files/2009/11/bajtin-teoria-y-estetica-de-

Boix, V. (1998) "Más allá de la revolución cognitiva". Zona Educativa, pp. 55-57.

Chavalier, J. (1999) Diccionario de símbolos. Sexta edición. Imprenta Tesys, Barcelona.

Chen, J. (2004) "El cronotopo de Indias y el sujeto afro-caribeño: recepción de Cocori". Kañina, Revista Artes y Letras. Universidad de Costa Rica. Volumen XXVIII, N. ${ }^{\circ}$ especial, pp. 33-40. Recuperado el día 27 de junio de 2014, desde: http:// N. especial, pp. 33-40. Recuperado el dia 27 de jun
www.vinv.ucr.ac.cr/latindex/kanina002/kan-28-04.pdf

Galante, K. (2007) Asking Directions: The Rules of the Game. The Tico Times. 04 de mayo, Weekend, W3. Me 04 de mayo, Weekend, W3. Material para los cursos de Claves Culturales I y II. Tomo II, página 82I Semestre del 2009 Maestría de Español como Segunda Lengua,
Universidad de Costa Rica, San José.

Gardner, H. (2001) La inteligencia reformulada. Las inteligencias múltiples en el siglo XXI. Barcelona: Editorial Pidós, SAICF.

Gustafsson, J. (2004) "El cronotopo cultural, el estereotipo y la frontera del tiempo: la preterización como estrategia de representación del "Otro". Revista de
estudios culturales de la Universitat Jaume I. Vol. I, pp. 137 - 147. Recuperado el 3 de febrero de 2015, desde: http://www I. Voco. l, pp. 137 - 147 . Recuperado e le/106029/148007.

Heidegger, M. (1951) Construir, habitar, pensar. Recuperado el 3 de febrero de 2015, desde: http://eskenazi.net16.net/heideggerhabitar.html

Perkins, D. (1993) "Teaching for Understanding": The Professional Journal of the American Federation of Teachers. Vol 17, número 3, pp. 8, 28-35. Recuperado
el 15 de febrero de 2015, desde: http://www.exploratorium.edu/ifi/resources/ workshops/teachingforunderstanding.html

Perkins, D. y Blythe, T. (1994) "Putting Understanding up-front" Educational Leadership 51 (5), 4-7. Traducción Antología: Tomo I: Material para los cursos de Claves Culturales I y II por María Amoretti Urtado: "Ante todo la comprensión" p. 1-6. 
Pogré, P. (2001) Capítulo 3: “Enseñanza para la comprensión. Un marco para innovar en la intervención didáctica" Escuelas del futuro II. Cómo planificar las escuelas que innovan de Aguerrondo Inés y colaboradoras. Editorial Papers. Recuperado el 5 de febrero de 2015, desde: http://latitud-nodosur.org/lMG/pdf/ Pogre-_EpC-_Un_marco_para_innovar.pdf

Ritchhart, R. y Perkins, D. (2000) "Life in Mindful Classtoom: Nurturing the Disposition of Mindfuulness". Traducción "La vida en Aula Reflexiva (mindful)" Journal of Social Issues. Volumen 56, Número 1, pp27-47. Cambridge: Harvard University. Recuperado el 6 de enero de 2015, desde: http://www.walthampublicschools. org/Math/LifeinTheMindfulClassroom.pdf

Lara-Martínez, R. (2003) "Acerca de las desacralizaciones del mundo moderno" En Perkins, D. y Blythe, T. (1994) "Putting Understnding up-front". Educational Leadership, 51 (5). Pp. 4-7. Traducción: "Ante todo la comprensión" pp.1-6.

(2006) Del paisaje como identidad cultural. Gilberto González y Contreras. Istmo. Revista virtual de estudios literarios y culturales centroamericanos. No. 12 enero - junio. Tecnológico de Nuevo México, Estados Unidos. Editor: Casa de los Tres Mundos, Instituto de Historia de Nicaragua y Centroamérica (IHNCA-UCA), Centro de Investigación en Identidad y Culturas Latinoamericanas (CIICLA), The College of Wooster y Denison University. Recuperado el 16 de setiembre de 2014, desde: http://istmo.denison.edu/n12/articulos/paisaje.html

Ministerio de Educación, Cultura y Deportes, Subdirección General de Cooperación Internacional, para la edición impresa. Madrid (2002) Marco Común Europeo de Referencia para las Lenguas: Aprendizaje, Enseñanza, Evaluación. Recuperado el 15 de noviembre de 2013, desde: http://cvc.cervantes.es/obref/marco/cvc_mer.pdf

Molina, I. (2008) Costarricense por dicha: identidad nacional y cambio cultural en Costa Rica durante los siglos XIX y XX. 3. . . Reimpresión. Editorial de la UCR, San José, Costa Rica.

Montero, D. (2014) “La (Re)Presentación del Espacio Nacional en las Manifestaciones Pictóricas "Panal" (1991) y "Enjambre" (1994) del Artista Costarricense Rafael Ángel "Felo" García". En Káñina, Rev. Artes y Letras, Univ. Costa Rica XXXVIII (2): 191-207, ISSN: 2215-2636. Recuperado el 16 de enero de 2015, desde: http:// revistas.ucr.ac.cr/index.php/kanina/article/download/15654/15005

Murillo, E. (2000) “¡UUUUUPEEE! Llamando ante la casa de adobe. Análisis sociocrítico del "símbolo patrio" de la casa de adobe, en su dimensión pictórica" Káñina. Revista Artes y Letras. Universidad de Costa Rica. Vol. XXIV (2), pp. 111-124

Salazar, C. (1990) Cuentos de Angustias y Paisajes. Reimpresión. Editorial El Bongo. San José, Costa Rica. 